\title{
Application of Nano Coating to ACSR conductor for the Protection of Transmission lines against Solar Storms, Surface Flashovers, Corona and Over voltages
}

\author{
D. Edison Selvaraj ${ }^{\dagger}$, K. Mohanadasse *, C. Pugazhendhi Sugumaran** and R. Vijayaraj***
}

\begin{abstract}
Nano composite materials were multi-constituent combinations of nano dimensional phases with distinct differences in structure, chemistry and properties. Nano particles were less likely to create large stress concentrations and thereby can avoid the compromise of the material ductility while improve other mechanical properties. Corona discharge was an electrical discharge. The ionization of a fluid surrounding a conductor was electrically energized. This discharge would occur when the strength of the electric field around the conductor was high enough to form a conductive region, but not high enough to cause electrical breakdown or arcing to nearby objects. This paper shows all the studies done on the preparation of nano fillers. Special attention has given to the ACSR transmission line conductor, $\mathrm{TiO}_{2}$ nano fillers and also to the evaluation of corona resistance on dielectric materials discussed in detail. The measurement of the dielectric properties of the nano fillers and the parameters influencing them were also discussed in the paper. Corona discharge test reveals that in $0 \% \mathrm{~N}$ ACSR sample corona loss was directly proportional to the applied line voltage. No significant change in corona loss between $0 \% \mathrm{~N}$ and $1 \% \mathrm{~N}$. When $\mathrm{TiO}_{2}$ nano filler concentration was increased up to $10 \% \mathrm{~N}$ fine decrement in corona loss was found when compared to base ACSR conductor, corona loss was decreased by $40.67 \%$ in $10 \% \mathrm{~N}$ ACSR sample. It was also found from the surface conditions test that inorganic $\mathrm{TiO}_{2}$ nano filler increases the key parameters like tensile strength and erosion depth.
\end{abstract}

Keywords: ACSR, $\mathrm{TiO}_{2}$, Nano filler, Corona, Surface flashover

\section{Introduction}

In A solar flare was defined as a sudden flash of brightness observed over the Sun's surface or the solar limb, which was interpreted as a large energy release. They were often followed by a colossal coronal mass ejection. The flare ejects clouds of electrons, ions, and atoms through the corona of the sun into space. These clouds typically reach Earth a day or two after the event. The term was also used to refer to similar phenomena in other stars, where the term stellar flare applies. Solar flares strongly influence the local space weather in the vicinity of the Earth. They can produce streams of highly energetic particles in the solar wind, known as a solar proton event. These particles can impact the Earth's magnetosphere and present radiation hazards to spacecraft, astronauts and

$\dagger$ Corresponding Author: Dept. of Electrical and Electronics Engineering, Panimalar Engineering College, Chennai, India.

(edisonsivakasi@gmail.com)

* Dept. of Electrical and Electronics Engineering, St. Joseph's College of Engineering, Chennai, India.

(electricalresearchkmd@gmail.com)

** Dept. of Electrical and Electronics Engineering, CEG., Anna University, Chennai. (cpsugumar@gmail.com)

*** Dept. of Mech Engineering, Dhanalakshmi Srinivasan College of Engineering and Tech, Mamallapuram, Chennai, India. (vijayme2k@yahoo.co.in)

Received: October 12, 2014; Accepted: January 16, 2015
Power System components. Additionally, massive solar flares are sometimes accompanied by coronal mass ejections (CMEs) which can trigger geomagnetic storms that have been known to disable satellites and knock out terrestrial electric power grids for extended periods of time. Especially transmission lines were affected by solar storms. Over voltages were caused on power systems due to external and internal influencing factors. The voltage stress caused by over voltage can damage the transmission lines and equipments connected to the power system. A corona was a process by which a current flows from an electrode with a high potential into a neutral fluid, usually air, by ionizing that fluid so as to create a region of plasma around the electrode [1-4]. The ions generated eventually pass charge to nearby areas of lower potential, or recombine to form neutral gas molecules. Corona discharge usually forms at highly curved regions on electrodes, such as sharp corners, projecting points, edges of metal surfaces, or small diameter wires. The high curvature causes a high potential gradient at these locations, so that the air breaks down and forms plasma there first [5-7]. In order to suppress corona formation, terminals on high voltage equipment are frequently designed with smooth large diameter rounded shapes like balls or toruses, and corona rings are often added to insulators of high voltage transmission lines. 
Corona discharge was generally undesirable in:

Electric power transmission due to the following reasons

- Power loss

- Audible noise

- Electromagnetic interference

- Purple glow

- Ozone production

- Insulation damage

Electrical components such as transformers, capacitors, electric motors and generators. Corona progressively damages the insulation inside these devices, leading to premature equipment failure. One form of attack was ozone cracking of O-rings.

\section{Static electricity discharge.}

Nano fillers refer to those fillers of sub-100 nm size in at least one dimension. The small size of the fillers leads to an exceptionally large interfacial area in the nano composites [8-10]. Nano particles are also less likely to create large stress concentrations and thereby can avoid the compromise of the material ductility while improve other mechanical properties [11-13]. The method of synthesis often influences the size and properties of the nano particles. The nano particle size was dependent on the kinetics of nucleation and growth from a supersaturated solution as well as processes such as coarsening, oriented attachment, and aggregation, which tend to occur at longer times.

\section{Characterizations and Synthesization of Nano Fillers}

\subsection{Material characterization}

The selection of the nano filler plays a very important role in the enhancement of properties of the nano fluid. The first step in selection of nano fillers was based on the method of preparation. Since the ACSR transmission line conductor was used as a base material, the choice of the material must be made based on its thermal as well as stress-strain properties.

\subsection{Sample preparation}

Initially $125 \mathrm{gms}$ of the $\mathrm{TiO} 2$ powder were taken and subjected to grinding with the help of a planetary ball mill. The grinding was done for about 55 hours with an average speed of 348 rpm using 23 tungsten carbide balls. Only two-thirds of the bowl volume was filled by the grinding balls and the sample. One third was left free for the centrifugal action to be effective. After the ball milling process is over, a small amount of the sample was taken and Scanning electron microscopy analysis was done in order to determine the size of the resultant powder.

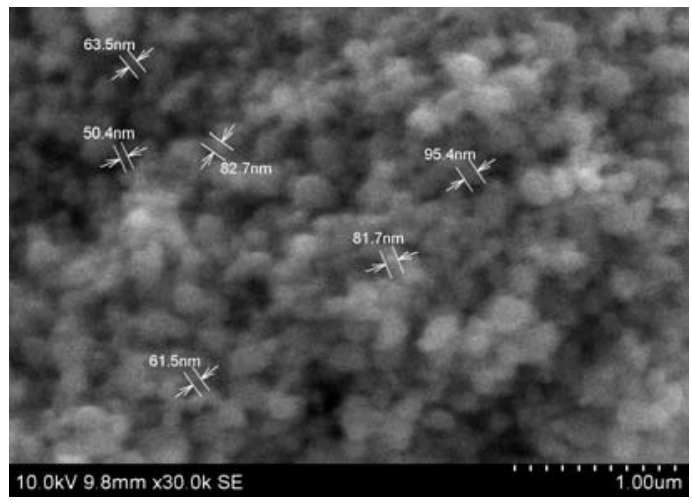

Fig. 1. SEM Image of nano size $\mathrm{TiO}_{2}$ fillers

From Fig. 1, it has been observed that the size of all the particles is below $100 \mathrm{~nm}$. Now in order to prepare the nano fluids, transformer oil was taken in a $500 \mathrm{ml}$ conical flask and the nano fillers of a particular concentration was added. Now the mixture was stirred by using a magnetic stirrer in order to prevent agglomeration and then mixed by using an ultrasonic mixer for about 8 hours to ensure uniform mixing of the nano filler in the base fluid.

\subsection{Synthesization of nano particles}

Nano particles or nano tubes can be synthesized artificially for specific materials using certain specific methods. Methods based on non-equilibrium thermodynamics include growth under kinetic limited or reaction controlled conditions and creation by artificial techniques. Nano tubes, nano particles, and some thin films are grown under reaction and kinetic limited conditions. Also lithography of all kinds, beam etching techniques of all kinds, probe microscope techniques, and combinations of these and other techniques form a part of this group. Some of the structures so grown can be thermally and chemically

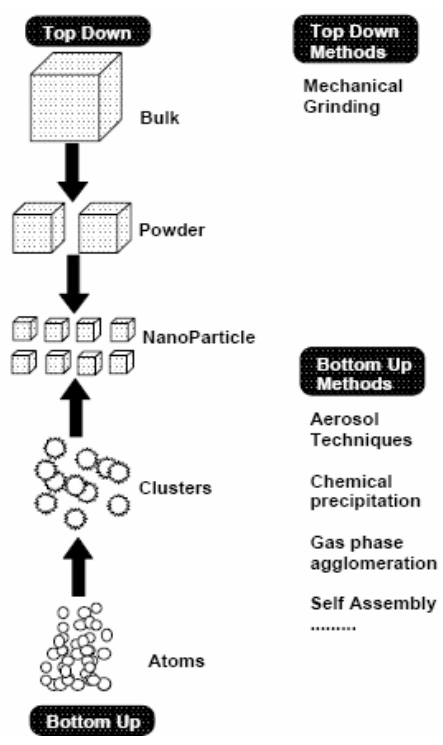

Fig. 2. Nano particles preparation method 
quite stable.

In this investigation the top down method approach using mechanical grinding was adopted. Mechanical attrition was a typical example of 'top down' method of synthesis of nano materials, where the material is prepared not by cluster assembly but by the structural decomposition of coarser-grained structures as the result of severe plastic deformation. This has become a popular method to make nano crystalline materials because of its simplicity, the relatively inexpensive equipment (on the laboratory scale) needed, and the applicability to essentially the synthesis of all classes of materials. The major advantage often quoted was the possibility for easily scaling up to tonnage quantities of material for various applications.

\subsection{ACSR conductor}

Aluminum conductor steel-reinforced cable (ACSR) was a specific type of high-capacity, high-strength stranded cable typically used in overhead power lines. The outer strands were aluminum, chosen for its excellent conductivity, low weight and low cost. The center strand was of steel for the strength required to support the weight without stretching the aluminum due to its ductility. This gives the cable an overall high tensile strength.

\section{Experimental Work}

\subsection{Corona discharge test}

The AC source was a transformer with maximum output voltage of $10 \mathrm{kVA}, 11 \mathrm{kV} / 100 \mathrm{kV}$. In this test a cage which has a smooth surface is used. The corona cage was $50 \mathrm{~cm}$ long and has a diameter of $10 \mathrm{~cm}$. Its thickness is measured as $1 \mathrm{~mm}$. For current measurements a corona ring is placed on the centre of corona cage. The ring was fit to corona cage and the ACSR conductor sample has been taken from this ring and was connected to a measuring device. Current measurements are done by using an oscilloscope which is connected to cage by the conductors fitted to cage with a $102.6 \Omega$ measuring resistor in series also with a Fluke 187

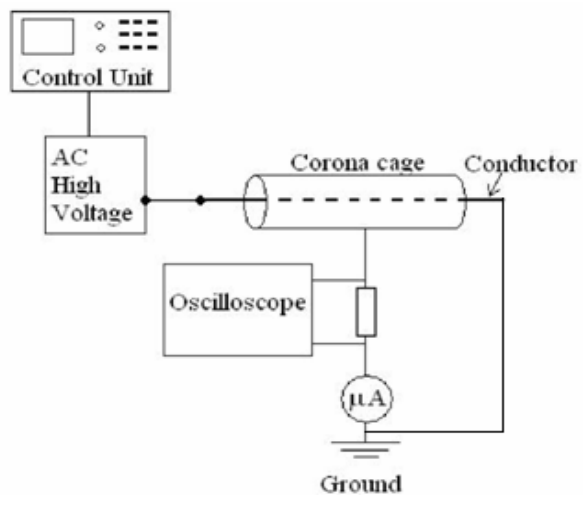

Fig. 3. Principle diagram digital multimeter. Principle scheme for corona measuring system was shown in the Fig. 3.

To measure the corona inception voltage, the applied voltage is gradually increased and the lowest voltage at which continuous corona occurs is noted. When measuring corona extinction voltage, applied voltage is raised \% 10 up to the voltage level which corona inception voltage is recorded. Then the applied voltage started to decrease until the corona noise cannot be heard and the harmonics were started to decline while monitoring from oscilloscope and control unit. Therefore to see the exact value of corona inception and extinction voltage levels, the rate of rise is chosen $500 \mathrm{~V} / \mathrm{s}$. The diameters for aluminum conductors and steel core are selected as $3.18 \mathrm{~mm}$. The corona discharge test was conducted by measuring the corona inception and corona extinction voltage. For both unfilled and nano filled ACSR conductor samples this corona discharge test conducted. The ACSR conductor was coated with different $\mathrm{TiO}_{2}$ concentrations. The experimental results have been tabulated as follows.

From Table 1 and graph1, it has been well established that there was no significant improvement in inception voltage, as comparing $1 \% \mathrm{~N}$ ACSR sample with base unfilled ACSR sample. But significant results revealed when the concentration was increased up to $10 \% \mathrm{~N}$. when the nano filler concentration increases, corona inception voltage increases. This leads to the increment of corona resistance value. The results are given in Table 2.

Corona power loss calculation reveals that increasing the $\mathrm{TiO}_{2}$ nano filler concentration decreases the power loss. Initially power loss is experimentally increased with the applied voltage to the conductor. And from Table 1, corona inception and extinction voltage depends on the filler concentration and increase with it. It clears that $\mathrm{TiO}_{2} \mathrm{Nano}$ filler increases the corona inception voltage and thereby

Table 1. Corona discharge test results

\begin{tabular}{|c|c|c|}
\hline $\begin{array}{c}\text { ACSR Conductor } \\
\text { Sample Type } \\
\end{array}$ & $\begin{array}{c}\text { Uiv, (Corona Inception } \\
\text { Voltage, } \mathrm{kV} \text { ) } \\
\end{array}$ & $\begin{array}{c}\text { Uev, (Corona Extinction } \\
\text { voltage }, \mathrm{kV})\end{array}$ \\
\hline Unfilled Sample & 64.2 & 61.9 \\
\hline $1 \% \mathrm{wt} \mathrm{TiO}_{2}$ & 64.7 & 62.1 \\
\hline $3 \% \mathrm{wt} \mathrm{TiO}_{2}$ & 67.3 & 65.2 \\
\hline $5 \%$ wt $\mathrm{TiO}_{2}$ & 69.8 & 67.6 \\
\hline $10 \%$ wt $\mathrm{TiO}_{2}$ & 72.8 & 69.8 \\
\hline
\end{tabular}

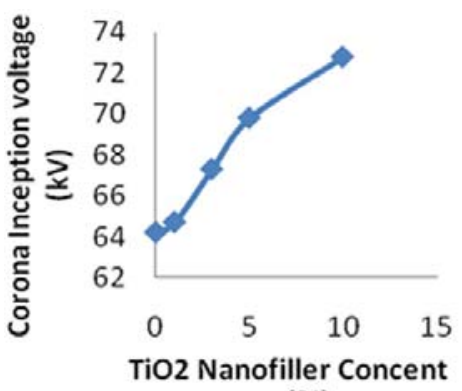

(\%)

Fig. 4. Corona inception voltage vs nano filler concentration 
Table 2. Calculated corona loss value

\begin{tabular}{|c|c|c|}
\hline $\begin{array}{l}\text { ACSR Conductor } \\
\text { Sample Type }\end{array}$ & $\begin{array}{c}\text { Corona Loss at inception } \\
\text { voltage (W) }\end{array}$ & $\%$ Decrease \\
\hline Unfilled Sample & 27.93 & $* * * * * *$ \\
\hline $1 \%$ wt $\mathrm{TiO}_{2}$ & 26.03 & 4.5 \\
\hline $3 \%$ wt $\mathrm{TiO}_{2}$ & 24.07 & 11.11 \\
\hline $5 \%$ wt $\mathrm{TiO}_{2}$ & 21.98 & 18.34 \\
\hline $10 \%$ wt $\mathrm{TiO}_{2}$ & 17.01 & 40.67 \\
\hline
\end{tabular}

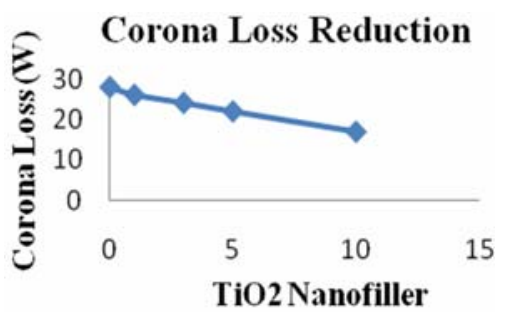

Fig. 5. Corona Loss vs Nano filler Concentration

corona resistivity keep increases, as filler concentration increases.

From Fig. 5 it was established that the calculated corona loss is reduced considerably with the increase in $\mathrm{TiO}_{2}$ nano filler concentration.

\subsection{Surface conditions test}

The ACSR sample conductor was fitted with suitable compression dead end clamps and the assembly was mounted on a tensile testing machine. Initially a load of $5 \mathrm{kN}$ was applied and free length of the conductor was measured. Circles were marked in three places, two near

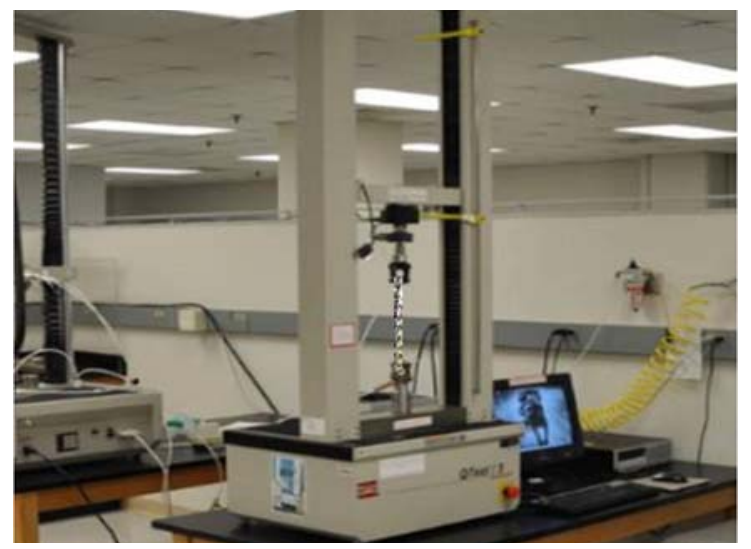

Fig. 6. Surface conditions test

Table 3. Surface conditions test Results

\begin{tabular}{c|c|c}
\hline Sample Type & Ultimate Breaking Load $(\mathrm{kN})$ & \% Increment \\
\hline Unfilled Sample & 36.65 & $* * * * * * *$ \\
\hline $1 \% \mathrm{wt} \mathrm{TiO}_{2}$ & 36.88 & 0.66 \\
\hline $3 \% \mathrm{wt} \mathrm{TiO}$ & 2 & 3.33 \\
\hline $5 \% \mathrm{wt} \mathrm{TiO}_{2}$ & 37.92 & 5.3 \\
\hline $10 \% \mathrm{wt} \mathrm{TiO}_{2}$ & 38.71 & 8.07 \\
\hline
\end{tabular}

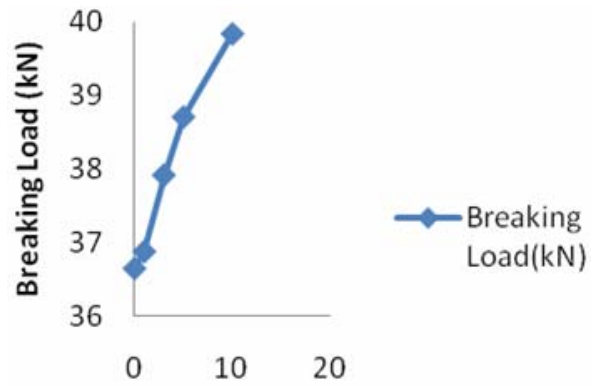

TiO2 concentration $(\%)$

Fig. 7. Nano filler concentration Vs Breaking Load

the compression end and one at the centre of the conductor. A Load of $50 \%$ was applied gradually and held for one minute. And after this period, the circles marked were checked for any distortion.

Then after the load was increased gradually till the rated UTS of the conductor was reached and held for one minute and then increased till the breakage of the conductor.

From Fig. 7, it has to be noted that Inorganic $\mathrm{TiO}_{2} \mathrm{Nano}$ filler increases the key parameter tensile strength. Table 3 emphasize this concept positively. From the surface conditions test is has been cleared that nano coated ACSR sample has higher tensile strength as compared to unfilled base ACSR sample.

\subsection{Surface erosion test}

To ascertain the concept that $\mathrm{TiO}_{2}$ nano filler increases the erosive resistivity, the surface erosion test was conducted. This test was aimed to calculate the surface degradation depth on the surface of both unfilled and nano coated ACSR conductor samples. The voltage applied was $72 \mathrm{kV}$ to each sample for 50 hours. One unfilled and 4 nano coated samples with different filler concentrations were used in surface erosion test. The degradation depth was measured after every 10 hours. The profilometer was used to measure these erosion depths on the sample surface. The power supply is a $10 \mathrm{kVA}, 11 \mathrm{kV} / 110 \mathrm{kV}$ transformer.

The sample degradation was represented by the maximum depth of the cone. It was measured after every 10 hours. For all samples surface erosion depth was measured using profilometer. From table 4 it reveals that the surface degradation depth was initially high. No significant variation in height of the depth occurred for unfilled and $1 \%$ N ACSR sample. But considerable changes in height of the erosion depth occur on the ACSR sample surface while higher concentration of $\mathrm{TiO}_{2}$ nano filler was introduced. As zchannel was arrested considerably. Paths of erosion in filled samples are zigzag as they avoid the filler particles. Addition of nano fillers would create an obstruction to destruction as the nano fillers are more discharge resistant as compared to the unfilled surface portion.

From both graphs 8 and 9, it was observed that the 
Table 4. Degradation depth results

\begin{tabular}{c|c|c|c|c|c}
\hline ACSR Sample & \multicolumn{5}{|c}{ Erosion Depth $(\mu \mathrm{m})$} \\
\hline Unfilled Sample & 8.2 & 8.8 & 9.7 & 11.4 & 13.7 \\
\hline $1 \%$ wt $\mathrm{TiO}_{2}$ & 8.2 & 8.7 & 9.5 & 11.1 & 13.4 \\
\hline $3 \%$ wt $\mathrm{TiO}_{2}$ & 7.6 & 8.3 & 9.1 & 10.7 & 13.1 \\
\hline $5 \%$ wt $\mathrm{TiO}_{2}$ & 6.9 & 7.8 & 8.3 & 9.9 & 12.1 \\
\hline $10 \%$ wt $\mathrm{TiO}_{2}$ & 5.2 & 6.4 & 7.2 & 8.5 & 10.8 \\
\hline
\end{tabular}

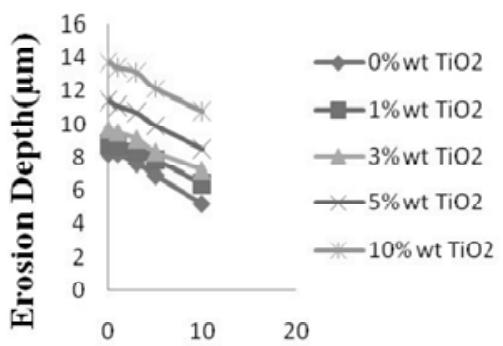

TiO2 nanofiller concentration(\%)

Fig. 8. Nano filler concentration vs erosion depth

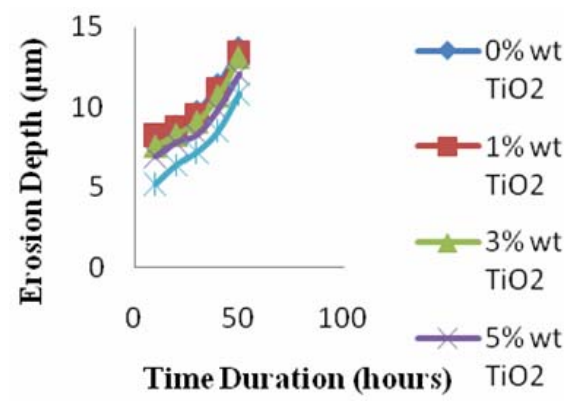

Fig. 9. Time duration vs erosion depth

erosion depth on the sample surface was reduced, as the nano filler concentration and time duration increases.

\subsection{Corona eroded surfaces}

There was no significant difference between base ACSR sample and $1 \%$ wt $\mathrm{N}$ samples. Surface erosion on $0 \% \mathrm{wt} \mathrm{N}$ and $1 \%$ wt $\mathrm{N}$ seemed to have similar degradation channel. As the $\mathrm{TiO}_{2}$ nano filler concentration was increased up to $3 \%$, erosion channels was arrested considerably. As compared to base ACSR conductors, $4.5 \%$ decrement in erosion depth was found on the surface of $3 \% \mathrm{~N}$ nano coated ACSR sample. Considerable reduction in surface erosion was observed, as the $\mathrm{TiO}_{2}$ nano filler was increased up to $5 \%$ concentration. Thereby surface erosion channel was arrested in the presence of nano filler particles. Compared to base ACSR sample, erosion channel was reduced with $11.6 \%$ rate in $5 \% \mathrm{~N}$ ACSR Sample. Fine improvement in degradation depth reduction was found on the surface of $10 \% \mathrm{~N}$ ACSR sample. Compared to base ACSR sample, erosion channel was reduced with $21.8 \%$ rate in $10 \% \mathrm{~N}$ ACSR Sample. From the above figures, it was established that the surface erosion was very high on base ACSR conductor sample. The erosion channel gets reduced when nano filler concentration increases considerably. There is not much variation in erosion depth between base conductor and $1 \% \mathrm{~N}$ filled sample. When $3 \% \mathrm{~N}, 5 \% \mathrm{~N}$ fillers added to the ACSR sample, then surface erosion reduced considerably. As the nano fillers are discharge resistant, erosion channels were arrested. Thereby rate of growth of erosion channel was reduced. In $10 \% \mathrm{~N}$ ACSR samples surface erosion channel seemed to have lesser depth as compared to base conductor sample.

\section{Conclusions}

The ultimate aim of this project was to measure the erosion depth on the surface of ACSR transmission line conductor and to decrease the surface flash over and also to reduce the corona loss. This work presented in this thesis represents the preliminary study that demonstrates the feasibility of the approach. A detailed literature review about nano filler preparation and characterization, dielectric characteristics and the parameters affecting them has been done. $\mathrm{TiO}_{2}$ nano fillers were synthesized using planetary ball milling and the size of the particles was analyzed using Scanning electron microscopy. It was found that the size of $\mathrm{TiO}_{2}$ nano particles was between $50.4 \mathrm{~nm}$ to $90.4 \mathrm{~nm}$. The standard tests been done according to the relevant standards. Corona losses were calculated for both filled and unfilled ACSR samples through corona discharge test and the characteristics of $\mathrm{TiO}_{2}$ nano filler confirmed by corona erosion and surface conditions test. Corona discharge test reveals that in $0 \% \mathrm{~N}$ ACSR sample corona loss is directly proportional to the applied line voltage. No significant change in corona loss between $0 \% \mathrm{~N}$ and $1 \% \mathrm{~N}$. When $\mathrm{TiO}_{2}$ nano filler concentration was increased up to $10 \% \mathrm{~N}$ fine decrement in corona loss was found. Compared to base ACSR conductor, corona loss was decreased by $40.67 \%$ in $10 \% \mathrm{~N}$ ACSR sample. It also found from the surface conditions test that inorganic $\mathrm{TiO}_{2}$ nano filler increases the key parameters like tensile strength and erosion depth.

\section{References}

[1] G.Iyer, R.S.Gorur (2012), “Corona Resistance of Dielectric materials” Experiment Results and Modelling, IEEE.

[2] Bin Ma, Stanislaw M.Gubanski, Krivda (2009), "Dielectric Properties and Resistance to corona and ozone of Epoxy Compositions Filled with Micro and Nano filler", IEEE.

[3] M. Abdel saleem and D.shamloul (1989), "Corona power loss calculation for three phase transmission lines", IEEE.

[4] R.M. Morris, "An investigation of corona loss and RIV from transmission line conductors at high Direct Voltages, IEEE. 
[5] Takahiro Imai, Fumio Sawa (2007), "Roles of Fillers on Properties of Nano- $\mathrm{TiO}_{2}$ and Micro- $\mathrm{SiO}_{2}$ Filler Mixed Composites", IEEE.

[6] Vincent T.Morgon, "Effect of AC, DC current, power frequency, temperature on the ACSR conductors", IEEE.

[7] Fussio Sawa, "Nano filler combination enabling practical use of nano composites", IEEE.

[8] A.E.Loxton and A.C.Britten, "The measurement and assessment of corona power loss on $400 \mathrm{kV}$ transmission lines", IEEE.

[9] Indranil Manna (2009), 'Synthesis, Characterization and application of nanofluid-an overview', Journal of the Indian Institute of Science, Vol.89.

[10] Tae-Keun Hong and Ho-Soon Yang (2005), 'Nanoparticle Dispersion dependent Thermal conductivity', Journal of the Korean Physical Society.

[11] Irwin, P. C Cao, Y. Bansal (2003), "Thermal and mechanical properties of polymide nanocomposites" Electrical Insulation and Dielectric Phenomena, CEIDP.

[12] Kozako, M. Fuse, N. Ohki(2004), "Surface Degradation of Polymide nano composites caused by partial discharge using IE", IEEE.

[13] Lewis, T. J(1994), "Nanometric Dielectrics" Dielectrics and Electrical Insulation, IEEE.

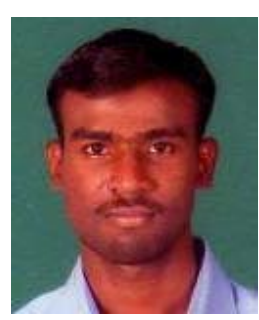

D. Edison Selvaraj $\mathrm{He}$ was born in Sivakasi on $13^{\text {th }}$ November 1985 . He received the B.E. degree in Electrical and Electronics Engineering from Sree Sowdambika College of Engineering affiliated to Anna University, Chennai in 2007 and M.E. degree in HighVoltage Engineering from Anna University, Chennai, Tamilnadu, India in 2010. He obtained Sixteenth Rank in B.E. degree and First Rank in M.E. degree. He has 5 years of teaching experience in various Engineering Colleges. He has published 150 papers in various International Journals, Conferences and Symposiums. He has attended various Workshops, Seminars, FDP, Short term courses and training programs. He received Shiksha Rattan Puraskar Award from IIFS, New Delhi. His name was also nominated for various awards such as Rajiv Gandhi Excellence Award, Glory of India Gold Medal, Pride of India Gold Medal, Best Citizens of India Award and so on. His biography was recognized in Marquis Who's Who, Asia / Pacific Who's Who and International Biographical Center. He was appointed as technical paper reviewer for various International Journals. He was appointed as Guest and Lead Editor for many reputed International Journals. He was appointed as Technical Committee Member for many International Conferences. He was doing research in the Applications of Nano technology in Electrical Engineering. His area of interest was Nano Dielectrics, Nano Motors, Nano Transformers, Nano Capacitors and Nano Electrical Apparatuses. He was the member of various Professional bodies like IEEE, ISTE, ACEEE, IAENG, IACSIT, UACEE, IDES, IETE and SCIEI. Presently, he was working as Assistant Professor in the Department of Electrical and Electronics Engineering, Panimalar Engineering College, Chennai, India and Guest Faculty in the Department of Electrical and Electronics Engineering, College of Engineering, Guindy, Anna University, Chennai, India.

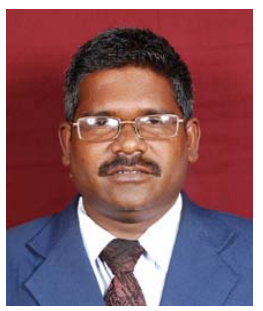

K.Mohanadasse He holds a B.Tech. in Electrical and Electronics Engineering from Pondicherry University, M.E. in Power Systems Engineering from Annamalai University and a Ph.D. Scholar in Electrical Engineering in Anna University, Chennai, India. At present, he holds the post of Associate Professor in EEE, St. Joseph's College of Engineering, Chennai-600 119. His research areas of interest include power quality, power electronics applications to power systems.

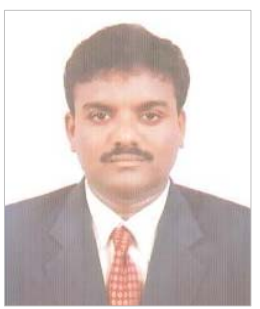

C. Pugazhendhi Sugumaran $\mathrm{He}$ received the B.E. degree in Electrical and Electronics Engineering from Government college of Engineering Tirunelveli, affiliated to Manonmanium Sundaranar University in 1997 and M.E. degree in High-Voltage Engineering from Anna University, Chennai, Tamilnadu, India in 2001. He was awarded Ph.D. in Electrical and Electronics Engineering from Anna University Chennai, in 2011. He has 17 years of teaching experience in various Engineering Colleges. He has published 60 papers in various International Journals, Conferences and Symposiums. He has attended various Workshops, Seminars, FDP, Short term courses and training programs. He was appointed as technical paper reviewer for various International Journals. His name was also nominated for various awards. He was doing research in the Applications of Nano technology in Electrical Engineering. His area of interest was Nano Dielectrics, Nano Motors, Nano Transformers, Nano Capacitors and Nano Electrical Apparatuses. He was the member of various Professional bodies like IEEE, ISTE, ACEEE, IAENG, IACSIT, UACEE, IDES, IETE and SCIEI. Presently, he was working as Associate Professor in the Division of High Voltage Engineering, Department of Electrical and Electronics Engineering, Guindy, Anna University, Chennai, India. 


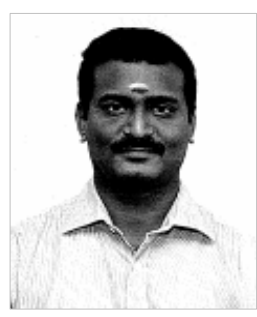

R. Vijayaraj He received B.E degree in Mechanical Engineering from Bharadhidasan University in 2002 and M.E degree in Energy Engineering from Anna University, Chennai, India in 2004. He was awarded Ph.D. in Mechanical Engineering from Anna University Chennai, in 2010. He has 14 years of Engineering College teaching experience. He has published 20 papers in various International Journals, Conferences and Symposiums. He has attended various Workshops, Seminars, FDP, Short term courses and training programs. He was appointed as technical paper reviewer for various International Journals. His name was also nominated for various awards. He was doing research in the Applications of Nano technology in Electrical Engineering. Presently, he was working as Professor in Dhanalaksmi Srinivasan College of Engineering \& Technology, Chennai, India. 